DOE Report No. DOE/ER/45622-3

\author{
Technical Progress Report
}

Title and Subtitle:

Principal Investigator:

Reporting Period:

Date Submitted:

DOE Sponsorship

and Grant No.:

\section{X-RAY and $\Gamma$-RAY SPECTROSCOPY of SOLIDS UNDER PRESSURE}

\author{
Robert L. Ingalls, Professor \\ Department of Physics, Box 351560 \\ University of Washington \\ Seattle, Washington 98195
}

November 1996 - December 1998

December 1998

Prepared for the U.S. Department of Energy

under Grant No. DE-FG03-97ER45622

This report was prepared as an account of work sponsored by the United States Government. Neither the United States nor the United States Department of Energy, nor any of their employees, makes any warranty, express or implied, or assumes any legal liability or responsibility for the accuracy, completeness, or usefulness of any information, apparatus, product, or process disclosed, or represents that its use would not infringe privately owned rights. Reference herein to any specific commercial product, process or service by trade name, mark, manufacturer, or otherwise, does not necessarily constitute or imply its endorsement, recommendation, or favoring by the United States Government or any agency thereof. The views and opinions of authors expressed herein do not necessarily state or reflect those of the United States Government or any agency thereof. 


\section{DISCLAIMER}

Portions of this document may be illegible in electronic image products. Images are produced from the best available original document. 


\section{Summary of Progress \\ X-Ray Spectroscopy of Solids under Pressure}

\section{Introduction}

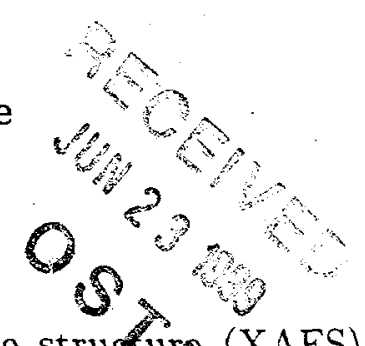

This report describes our recent synchrotron x-ray absorption fine structuge (XAFS) measurements on a number of systems that undergo pressure induced changes in local structure at high pressure. The reader should also refer to the accompanying renewal proposal for a more in-depth discussion of the general scope of this program, and its relevence to condensed matter science. We merely state that the methods here are aimed at using XAFS ${ }^{1}$ to probe the various phenomena that are caused by high pressure, especially including various structural, and/or electronic, changes or transitions. Our general technique ${ }^{2}$ is based upon a pressure cell which utilizes scintered boron carbide anvils, since diamond anvils generally produce Bragg glitches which spoil the high quality XAFS necessary for precision structural measurements. Sample pressure is determined at the beam-line by measuring and analyzing, via XAFS, the compression of some cubic material contained within the sample chamber. Recently we have extended this work to $77 \mathrm{~K}$ using helium gas for the applied force, rather than hydraulic oil.

This report period has been productive. The increased flux avaliable at the Stanford Synchrotron Radiation Laboratory (SSRL) has permitted our going to smaller beams, on the order of $300 \mu \mathrm{m}$ in diameter, for precision probing of the sample region. At the same time we have received ample amounts of beam time at SSRL, in part because of the high rating of our latest user proposal. We also were invited to share some of the beam time at the National Synchrotron Light Source (NSLS) assigned to the group of our collaborator, E. A. Stern.

Below we describe in some detail our recent work. Some of the pending papers are reports on systems that have been under study for some time and have been described in past progress reports and, as such, need not be described again here. 


\section{XAFS Measurements of Local Structural Changes in $\mathrm{KNbO}_{3}{ }^{3}$}

The ferroelectric material, potassium niobate, is of interest because there are conflicting reports $^{4,5}$ as to whether the transition is of the displacive or order-disorder type going from the high temperature cubic phase to the low temperature rhomboh phase. High pressure Raman studies suggest a transition to the paraelectric cubic structureas 9 -10 GPa in one case,${ }^{6}$ and in another case ${ }^{7}$ several displacive transitions in the range 2-15 GPa. Here we report careful measurements of the $\mathrm{Nb} \mathrm{K}$-edge XAFS in $\mathrm{KNbO}_{3}$, together with silver foil as pressure calibrant. The work was performed at SSRL. Fig. 1 shows typical data, and the enhanced signal caused by the high pressure.

The XAFS data for both the sample and calibrant were analyzed using the UWXAFS ${ }^{8}$ and FEFF $6^{9}$ methods. The general results show no definitive evidence of sharp local structural transitions at either temperature. We do find that the niobium atoms are displaced in the [111] directions from the centers of the oxygen octahedra at all pressures. However, as shown in Fig. 2, the magnitude of these displacements decreases gradually with increasing pressure by almost a factor of two in comparison with the lattice parameter, which only decreases by $3 \%$ within the same pressure range. Thus our work suggests that local rhombohedral distortions exist throughout the ferroelectric-paraelectric region, consistent with the XAFS temperature study of Ref. 4. These results strongly support an order-disorder mechanism for the ferroelectricity.

Our measurements extend out to the fifth nearest neighbor of the central absorbing niobium atoms. One of the parameters measured is the mean-square deviation in the various relative distances, $\sigma^{2}$. For the first three neighbors, corresponding to $\mathrm{O}(1), \mathrm{O}(2)$ and $\mathrm{Nb}(3)$, the $\sigma^{2}$ values decrease with increasing pressure, which is the normal stiffening behavior. However for $\mathrm{O}(4)$ and $\mathrm{Nb}(\overline{0})$, the $\sigma^{2}$ values anamalously increase with increasing pressure, indicating increasing static or dynamic disorder, something certainly not seen in any diffraction experiment. As for the $\mathrm{Nb}-\mathrm{O}(4)$ distance, we interpret its increasing $\sigma^{2}$ as a disorder in oxygen octahedral positions with pressure. This disorder, either a buckling or a rotation, 
indicates a lack of rigidity of the oxvgen sublattice, probably leading to some form of amorphization. The increasing disorder in $\mathrm{Nb}-\mathrm{Nb}(5)$, however is explained as a shortening of the correlation length between $\mathrm{Nb}-\mathrm{Nb}$ displacements. The latter could occur if the [111] type displacements in different domains had different orientations. FIGURES
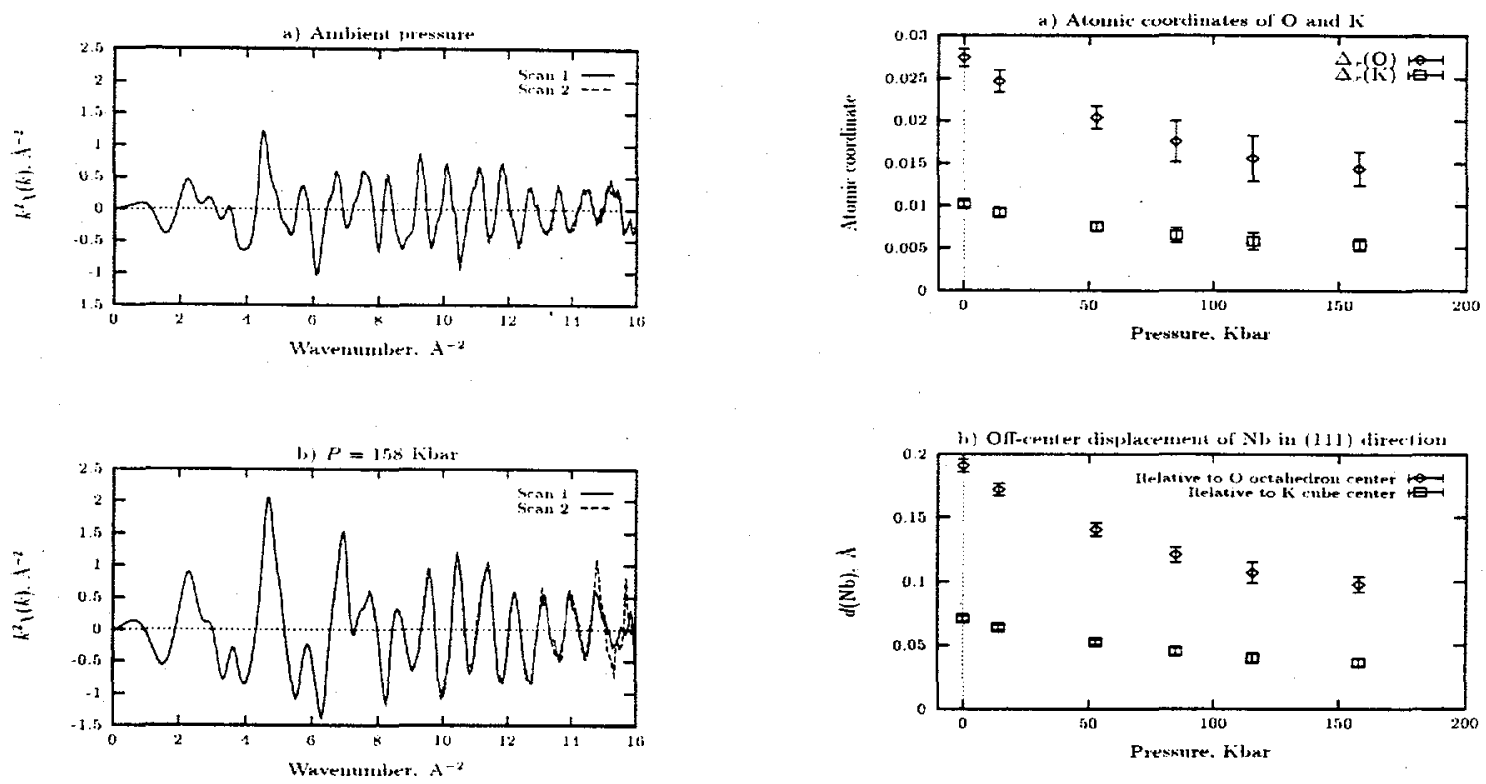

FIG. 1. Nb k-edge EXAFS of $\mathrm{KNbO}_{3}$ at

FIG. 2. $\mathrm{O}$ and $\mathrm{K}$ atomic displacements and ambient pressure and $15.8 \mathrm{GPa}$.

$\mathrm{Nb}[111]$ off-center displacements in $\mathrm{KNbO}_{3}$

The Effects of Pressure on the Local Structure of $\mathrm{K}_{1-x} \mathrm{Na}_{x} \mathrm{TaO}_{3}$ and $\mathrm{KTa}_{1-x} \mathrm{Nb}_{x} \mathrm{O}_{3} \cdot{ }^{10}$

The work discussed in this section is closely related to that in the previous section. In particular, $\mathrm{K}_{.15} \mathrm{Na}_{.85} \mathrm{TaO}_{3}$, has an antiferrodistortive distortion ${ }^{11,12}$, while $\mathrm{KTa}_{.13} \mathrm{Nb}_{.87} \mathrm{O}_{3}$ is ferroelectric. ${ }^{13}$ These were both studied at room temperature during an XAFS run at NSLS. The $\mathrm{K}$-edges of $\mathrm{Ta}$ and $\mathrm{Nb}$, respectively, were measured and copper was used as the pressure calibrant.

Examples of the absolute values of the radial-distribution/Fourier-transforms of the XAFS for the second system are shown in Fig. 3 along with standard fits in the range $1.0<\mathrm{r}<4.1 \AA$ based on the methods in Ref. 9. For $\mathrm{KTa}_{.13} \mathrm{Nb}_{.87} \mathrm{O}_{3}$ as shown in Fig. 4, the well known off-center $\mathrm{Nb}$ [111] displacements were observed to decrease with pressure, 
much as in the pure material $\mathrm{KNbO}_{3}$ and reflects the tendency toward the paraelectricity. The $\mathrm{NbO}_{6}$ octahedral rotation angles about the [111] axes in $\mathrm{K}_{.15} \mathrm{Na}_{.85} \mathrm{TaO}_{3}$ were observed to increase similar to the pressure effect in $\mathrm{ReO}_{3}{ }^{14}$.

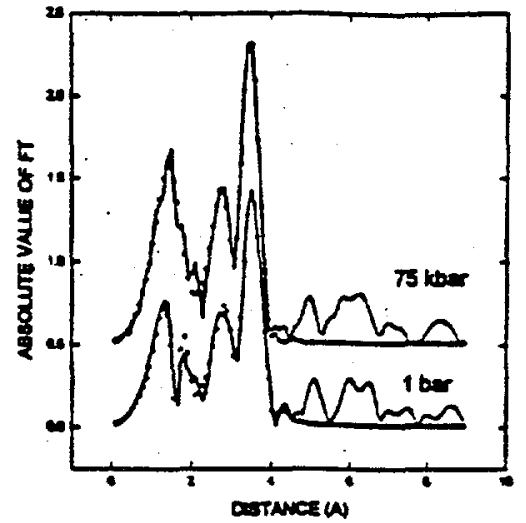

FIG. 3. Magnitude of the Fourier transform of $\mathrm{KNb}_{.87} \mathrm{Ta}_{.13} \mathrm{O}_{3}$.

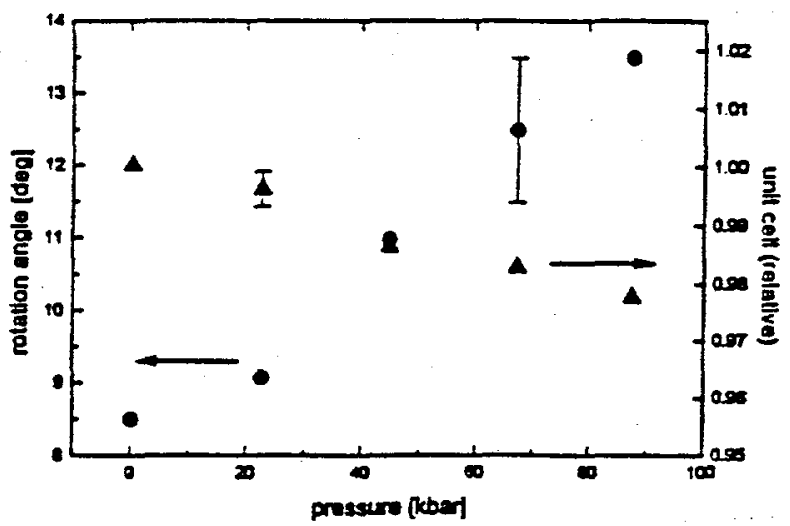

FIG. 4. $\mathrm{K}_{.15} \mathrm{Nb}_{.85} \mathrm{TaO}_{3}$ : Reduced cell parameters $(\Delta)$ and oxygen rotation angles $(\bullet)$.

Here, as for $\mathrm{KNbO}_{3}$ in the previous section, we find for $\mathrm{KTa} .{ }_{13} \mathrm{Nb}_{.87} \mathrm{O}_{3}$ that $\sigma^{2}$ associated with $\mathrm{Nb}-\mathrm{O}(4)$ also anomalously increases with pressure. This result can be understood if one assumes that pressure indeed induces disordered oxygen octahedral rotations. In the first approximation these rotations do not affect the $\mathrm{Nb}-\mathrm{O}(1)$ distances, but they do affect the $\mathrm{Nb}-\mathrm{O}(4)$, thus contributing to the large $\sigma^{2}$. Therefore there is a distribution of angles about the values in Fig. 4.

\section{XAFS Study of the Iron bcc-hcp Transition ${ }^{15}$}

Numerous studies ${ }^{16-18}$ have been performed to investigate the pressure driven iron bcchcp martensitic transition since its discovery by Bancroft et. al. ${ }^{19}$ This transition is known to be very sluggish and hysteretic. It starts at $13.0 \mathrm{GPa}$ and spans about $8.0 \mathrm{GPa}$ at room temperature. The atomic mechanism of this transition is still not well understood. For example, conflicting $c / a$ values of the hcp phase have been reported by Refs. 16 to 18 (see Fig. 5). Differences in pressure transmitting medium and method of determining the lattice constants from the diffraction peaks were suggested in Ref. 18 as a possible source of this conflict. Since monitoring the $c / a$ values are quite important in understanding the nucleation and growth behavior of the hcp and bcc phases during the for- 
ward and reverse transition, our further experimental XAFS investigation of this aspect of the transition was deemed necessary. Most of the previous studies on this transition used diffraction techniques, which probe the long range structure of the system. However, using XAFS, we were able to probe the structure during the transition from a local standpoint.

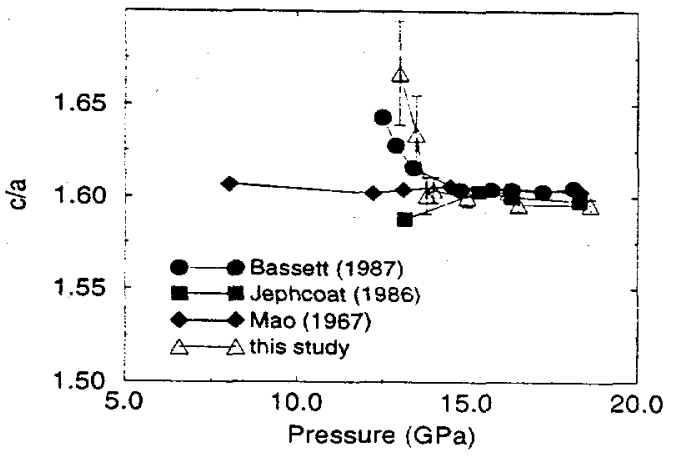

FIG. 5. Various $c / a$ results for hcp-Fe, including present results.

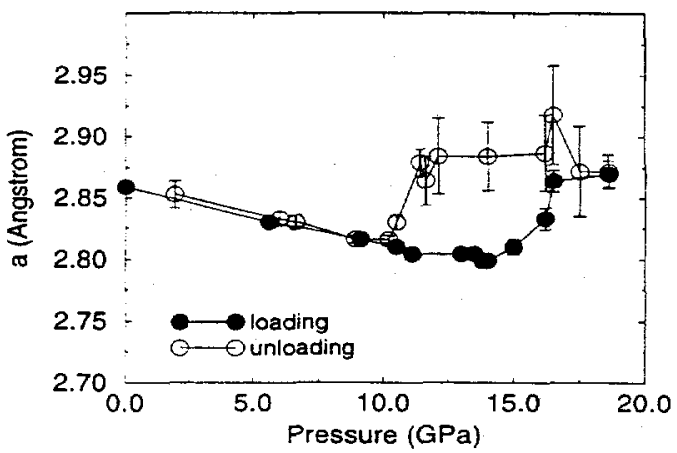

FIG. 6. Lattice constant for bcc-Fe during the bcc-hcp transition.

High pressure XAFS spectra of the Fe K-edge were obtained at SSRL and analyzed using $\mathrm{FEFF}^{9}$ programs. Copper was used as the pressure calibrant. For the resulting data analysis, the mixed-phase region was modeled as a simple mixture of bcc and hcp phases. General agreement with previous studies on the transition pressure and molar volume as a function of pressure was achieved in this study. The $c / a$ ratio was found to be anomalously large at the beginning of the forward transition (see Fig. 5), similar to the findings of Ref. 18. Also, as shown in Fig. 6, anomalously large lattice constants of the bcc phase, when the amount of the bcc phase became below approximately $10 \%$, were found for the first time.

We have investigated several models to explain these observed structural anomalies, based on some form of inter-phase strain. The results appear to rule out the model invoked by Refs. 16 and 18. However, a model first proposed by Burgers ${ }^{20}$, a two step process suggested to depict the zirconium bcc-hcp transition upon quenching from high temperature, was found to fit our data reasonably well. However we believe that inter-phase strain alone cannot fully explain these structural anomalies. Instead, two possible alternative intermediate phases are considered to help explain these anomalies. Both of these structures are actually suggested 
in Ref. 20. In one case, a fcc structure is formed, which would have c/a close to what we find. This would then be followed by a shear movement to produce the hcp phase. The second possibility, also following Ref. 20 , is that after a shearing along the [11̄i] direction and along the (112) plane, alternate layers of $(110)_{b c c} \|(002)_{h c p}$ planes might not immediately shift to their final positions. Instead the atoms in such planes could stay in somewhat in-between, off-positions, pushing the planes in question apart, giving an anomalously large $\mathrm{c}$ value for the interphase regions.

\section{XAFS Study of the B1-B2 Phase Transition in $\mathbf{R b C l}^{21}$}

Rubidium chloride undergoes a pressure induced phase transition from the $\mathrm{B} 1(\mathrm{NaCl}-$ type) to the $\mathrm{B} 2$ structure (CsCl-type) at approximately $0.5 \mathrm{GPa}$. The published equations of state of both phases above and below the transition ${ }^{22}$ make the material useful as a pressure calibrant in its own right. X-ray diffraction measurements, ${ }^{23}$ which show an orientational relationship between the phases, indicate the transition is martensitic. However the question of an intermediate structure occuring in such transitions has been raised, ${ }^{24}$ and the diffraction lines become too broad at the transition to rule out such a possibility. The purpose of the present study performed at SSRL was to combine this information with precision XAFS measurements that extend right through the transition itself and settle the above question.
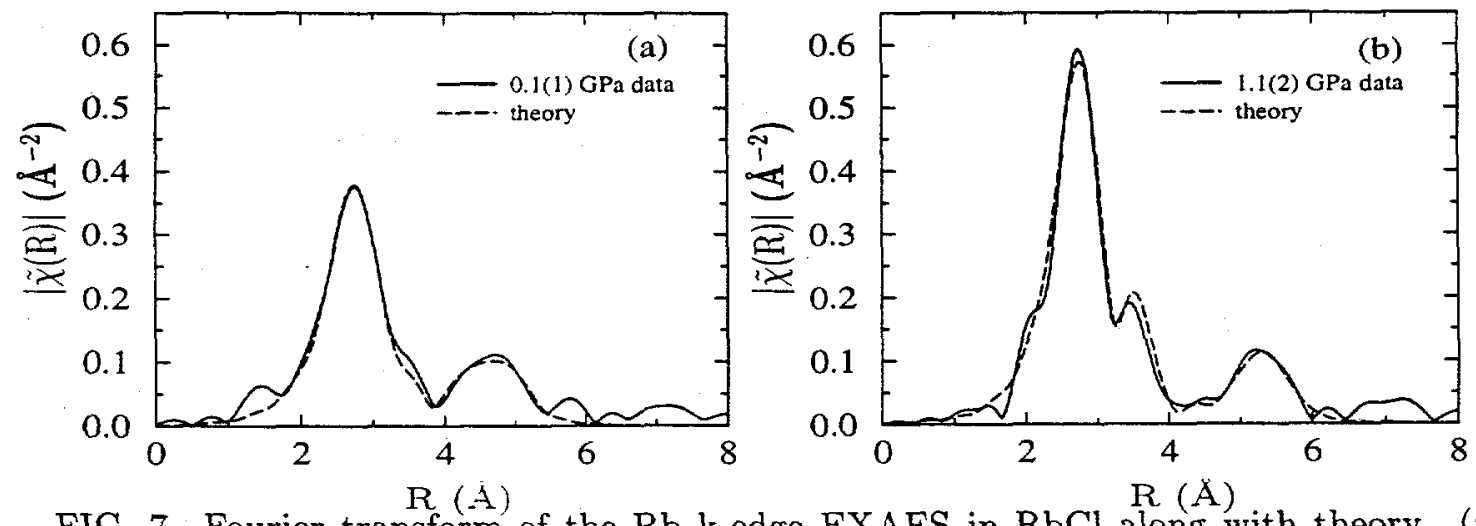

FIG. 7. Fourier transform of the Rb k-edge EXAFS in RbCl along with theory. (a) Model based on the B1 structure at ambient pressure. (b) Model based on the B2 structure at $1.1 \mathrm{GPa}$.

As shown in Fig. 7, our measurements on either side of the transition, combined with 
state-of-the-art theoretical analysis ${ }^{9}$ are in excellent agreement. Measurements at the transition itself, have been analyzed in two ways: 1) a mixture of the two phases, and 2) an intermediate $\mathrm{KOH}$ structure as suggested by Ref. 24. As indicated in Fig. 8, the mixed phase
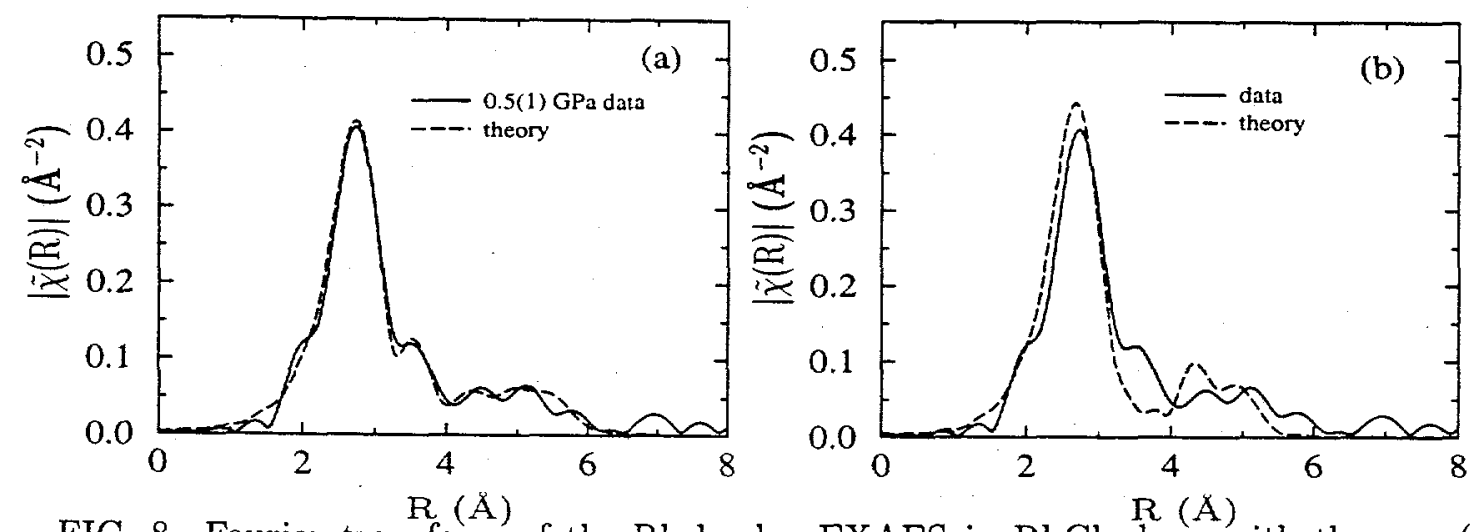

FIG. 8. Fourier transform of the Rb k-edge EXAFS in $\mathrm{RbCl}$ along with theory. (a) Model based on a mixture of B1 and B2 type structures. (b) Model based on an intermediate phase.

model perfectly fits the data, and the intermediate phase model does not. We note that this phase transition requires an excess pressure of about $0.2 \mathrm{GPa}$. Once the transition starts the system relaxes to a pressure of $0.5 \mathrm{GPa}$, which remains approximately constant until the transition is complete, in accordance with martensitic-like transitions. Our results also indicate that within the separate phases at the transition there is no more structural disorder than in the single phase regions, themselves.

\section{High Pressure Structure of the $\mathrm{AgCl}_{x} \mathrm{Br}_{1-x}$ System}

As with $\mathrm{RbCl}$ and most other alkali halides, $\mathrm{AgCl}$ has the $\mathrm{B} 1$ structure at ambient pressure and B2 structure at pressures above ca $20 \mathrm{GPa}$. Kusaba, et.al. ${ }^{24}$, using x-ray diffraction, have found the following intermediate phases at room temperature: KOH-type (HPI) from 9 to $13.5 \mathrm{GPa}$, TII-type (HPII) from 13.5 to $17.5 \mathrm{GPa}$. Furthermore they have determined lattice parameters at pressure for the various phases, and have obtained the relationship between the most primitive $\mathrm{KOH}$-type structure and the structure for each of the other phases. However this work did not determine the coordinates of the atoms within 
the unit cell for the HPI and HPII phases.

We have performed XAFS experiments of the $\mathrm{Ag} \mathrm{K}$-edge in $\mathrm{AgCl}$ at $150 \mathrm{~K}$, using niobium as the pressure calibrant. These experiments have enabled us, by means of $\mathrm{FEFF}^{9}$ multiple scattering analysis, to determine such coordinates. The $\mathrm{KOH}$ structure can be thought of as a distorted bct cell occuring in the B1 phase (Fig.9). The monoclinic distortion is such that identical layers are no longer directly over each other. That is, the angle between the $c$ axis and a-b plane is greater than $90^{\circ}$. Our results for the HPI phase are shown in Fig. 10.

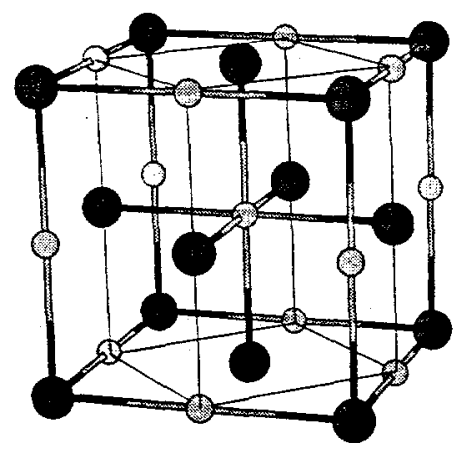

FIG. 9. The B1 structure with the KOH-

type cell outlined.

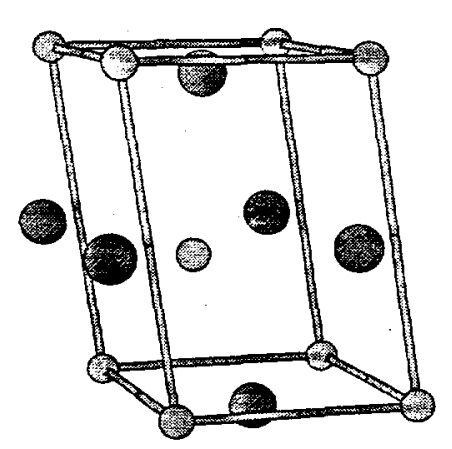

FIG. 10. Unit cell for the $\mathrm{AgCl}$ HPI structure (KOH-type) as determined by XAFS.

A picture of our results for the HPII phase would be similar, except with the angle increased to the point that a centered orthorhombic structure is the result. (A further increase in angle then produces the B2 structure.) In Fig. 11 we show a comparison with

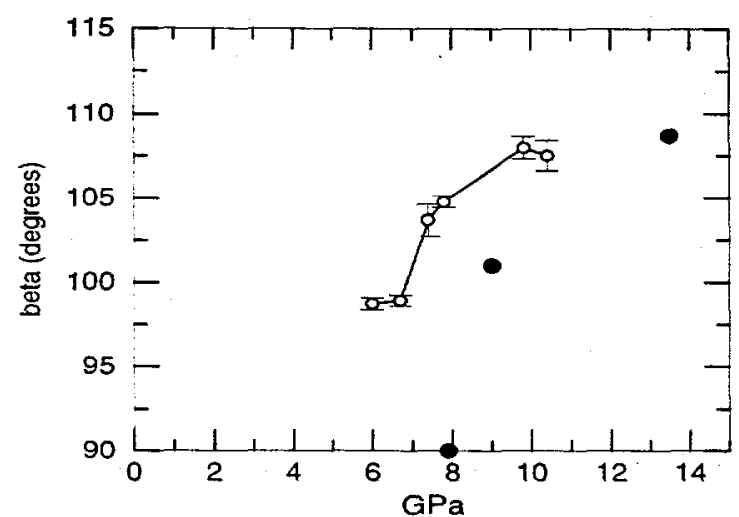

FIG. 11. The $\mathrm{AgCl}$ distortion angle, XAFS - open symbols, XRD - closed.

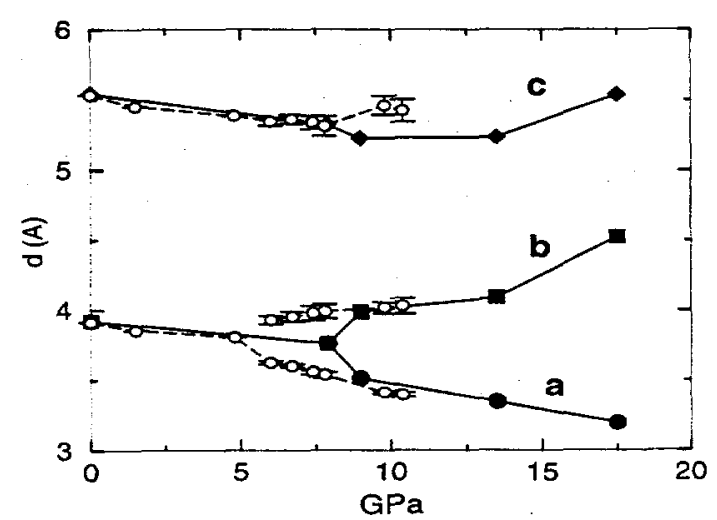

FIG. 12. The AgCl Lattice constants, XAFS - open symbols, XRD - closed. 
our angles and those of Ref. 24, and in Fig. 12, the lattice parameters. The agreement is quite good, with the exception at $150 \mathrm{~K}$ we observe the B1-HPI and HPI-HPII phase transitions to occur at lower pressures than in Ref. 24, which was based on room temperature results. While the change is not unexpected, it remains to verify whether the XAFS and XRD methods yield similar phase diagrams for this case. As we have seen earlier, such is by no means always the case.

At ambient pressure $\mathrm{AgCl}_{.5} \mathrm{Br}_{.5}$ also has the $\mathrm{B} 1$ structure. If we consider a site that is occupied by a $\mathrm{Br}$ or $\mathrm{Cl}$ the probability of finding one or the other is 50 percent. That is, the ion site is randomly occupied by a $\mathrm{Br}$ or $\mathrm{Cl}$. A buckling phenomenon has been proposed for this system ${ }^{27}$ which can be described as a displacement of the $\mathrm{Cl}$ and $\mathrm{Br}$ atoms from the line of $\mathrm{Ag}$ atoms. This mechanism may lead to amorphization at high

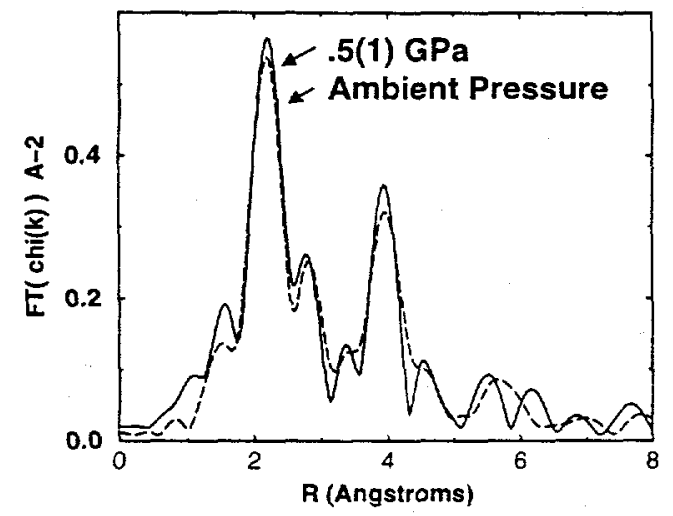

FIG. 13. Fourier transform of the $\mathrm{Ag}$ k-edge EXAFS in $\mathrm{AgCl}_{.5} \mathrm{Br}_{.5}$ at ambient pressure and $0.5 \mathrm{GPa}$.

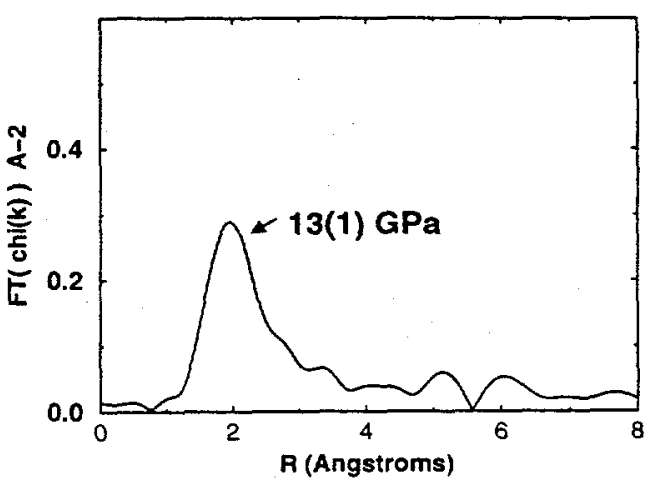

FIG. 14. Fourier transform of the Ag k-edge EXAFS in $\mathrm{AgCl}_{.5} \mathrm{Br} .5$ at $13 \mathrm{GPa}$.

pressure. This relatively simple crystal structure is ideal for studying such a process. XAFS is well suited to look for the buckling phenomenon, since it directly probes the distance between atoms, while diffraction techniques are less sensitive to disorder that averages to zero over many unit lengths.

Our results for this mixed system are shown in Figs. 13 and 14. At ambient pressure we see only one distance for the 1st nearest neighbors of $\mathrm{Cl}$ and $\mathrm{Br}$ atoms located at the center of each face of the unit cell at a distance of $2.8 \AA$, and only one $\mathrm{Ag}$ 2nd nearest neighbor 
distance located at the center of each edge of the unit cell at a distance of $4 \AA$. With the application of a small amount of pressure $(.5 \mathrm{GPa})$ we see a dramatic change in behavior. The $\mathrm{Ag}-\mathrm{Br}$ distance slightly decreases, but increases for $\mathrm{Ag}-\mathrm{Cl}$ along with the latter's $\sigma^{2}$. We also find a splitting of about $0.15 \AA$ in the Ag-Ag distances. This shows some support for the buckling phenomenon.

At $13 \mathrm{GPa}$, our highest pressure, we again find that all shells but the first are unobservable and even the first shell is diminished and very broad (Fig. 14). Our fit results also show that $\sigma^{2}$ has almost doubled for the Ag-Br distances and more than doubled for the Ag$\mathrm{Cl}$ distances. At the same time the bond lengths for both of these shells has significantly decreased. This behavior indicates a large degree of disorder at high pressure as well as possible amorphization.

\section{Pressure-induced Changes in the Local Structure of Pure and Optimally Doped $\mathrm{La}_{2-x} \mathrm{Sr}_{x} \mathrm{CuO}_{4}$}

Sr doping induces high $\mathrm{T}_{c}$ superconductivity in $\mathrm{La}_{2-x} \mathrm{Sr}_{x} \mathrm{CuO}_{4}$ for $0.07 \leq x \leq 0.25$ with $\mathrm{T}_{c}$ increasing to a maximum of $\sim 35 \mathrm{~K}$ at $x=0.15$ and then decreasing in the overdoped regime $^{25}$. Beside adding charge carriers (holes) to the $\mathrm{Cu}-\mathrm{O}$ planes, $\mathrm{Sr}$ substitution leads to structural changes that can be described, at a constant temperature, as a second order phase transition from orthorhombic (LTO) to tetragonal (HTT) symmetry ${ }^{25}$. Thus the contribution of these competing effects to the dependence of $\mathrm{T}_{c}$ on $x$ is hard to evaluate.

Pressure measurements allow studying the effect of structural changes on $T_{c}$ for a fixed carrier concentration. In this system, $\mathrm{T}_{c}$ is well known to increase linearly with pressure until the pressure-induced LTO-HTT phase transition takes place ${ }^{26}$. In the HTT phase $T_{c}$ is nearly independent of pressure. It is then of importance to determine what are the structural changes taking place with pressure in both phases and whether any correlation between them and $\mathrm{T}_{c}(\mathrm{P})$ can be established.

We performed XAFS experiments at the $\mathrm{Cu} \mathrm{K}$-edge of pure $\mathrm{La}_{2} \mathrm{CuO}_{4}$ at $300 \mathrm{~K}$ and of $\mathrm{La}_{1.85} \mathrm{Sr}_{0.15} \mathrm{CuO}_{4}$ at $\mathrm{T}=77 \mathrm{~K}$. The work was done at both SSRL and NSLS. For these samples 
and temperatures, the pressure-induced LTO-HTT phase transitions occur at $\mathrm{P} \approx 1.7 \mathrm{GPa}$ and $4.0 \mathrm{GPa}$, respectively ${ }^{28}$. Pressure was calibrated by measuring in-situ the XAFS of $\mathrm{Nb}$ powder.

Figs. 15 and 16 show the pressure dependence of the measured bond lengths for both $x=0.15$ and $x=0$ samples, respectively. (In these figures the results for $\mathrm{Cu}-\mathrm{O}(2)$ and $\mathrm{Cu}-\mathrm{La}$ are displaced vertically for clarity. The dotted line indicates the location of the LTO-HTT boundary.)

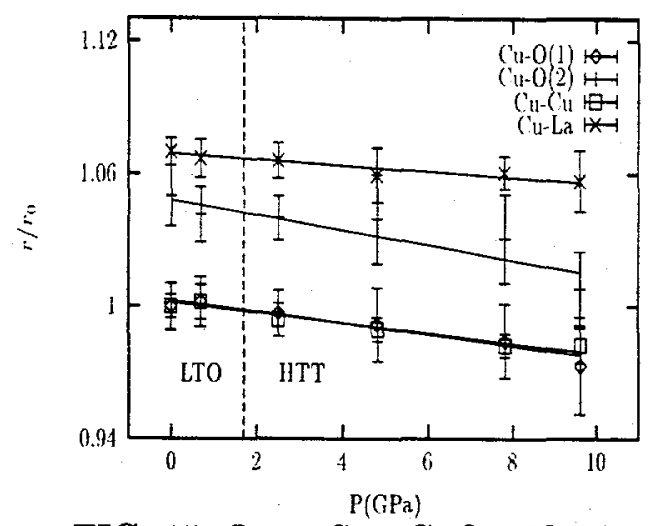

FIG. 15. $\mathrm{La}_{1.85} \mathrm{Sr}_{.15} \mathrm{CuO}_{4}$ : Normalized

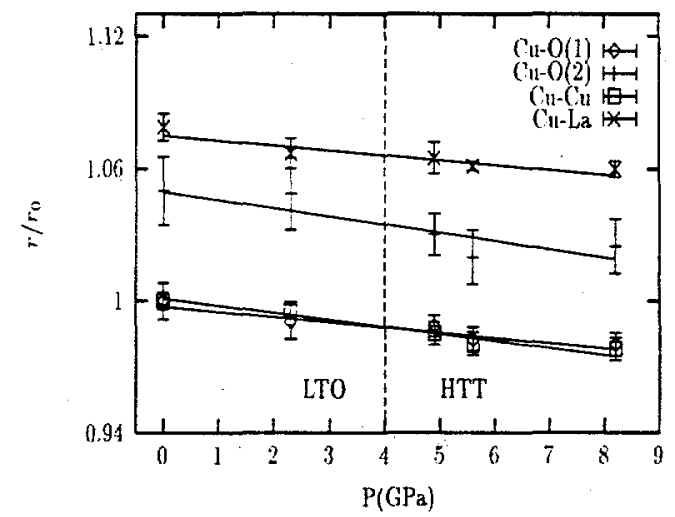

FIG. 16. $\mathrm{La}_{2} \mathrm{CuO}_{4}$ : Normalized

distances at $300 \mathrm{~K}$.

It is clear that no significant differences exist in the compressibility of these bonds across the LTO-HTT phase transition, indicating that the peculiar $T_{c}(\mathrm{P})$ relation is more likely determined by correlated changes in the electronic structure of this compound. It is worthwhile noting, however, the larger than expected compressibility obtained for the apical $\mathrm{Cu}-\mathrm{O}(2)$ bond length which is significantly larger than the $c$ axis compressibility found by diffraction. Even though the pressure induced changes in the $\mathrm{Cu}-\mathrm{O}(2)$ distance could enhance the hole content of the $\mathrm{Cu}-\mathrm{O}$ layers by enhancing charge transfer through enhanced hybridization of $\mathrm{Cu} 3 \mathrm{~d}_{3 z^{2}-r^{2}}$ and $\mathrm{O} 2 \mathrm{p}_{z}$ orbitals, it is by itself not enough to account for the apparent saturation of $T_{c}(P)$ in the HTT phase.

\section{Chain Buckling in $\mathrm{YBa}_{2} \mathrm{Cu}_{3} \mathrm{O}_{7-\delta}$}

During this report period an analysis of an experiment begun several years earlier was completed, namely a study of the superconductor, $\mathrm{YBa}_{2} \mathrm{Cu}_{3} \mathrm{O}_{6.95}$. This XAFS experiment 
of the $\mathrm{Cu}$ K-edge was performed at $80 \mathrm{~K}$, and the pressure calibrant was germanium.

The results indicate a buckling in the $\mathrm{Cu}(1)-\mathrm{O}(4)-\mathrm{Cu}(2)$ chains through the $\mathrm{O}(4)$ atoms. Using multiple scattering analysis, it is found that the buckling angle from colinearity, $\beta$, increases rapidly at low pressures then saturates at $\sim 6.5 \mathrm{GPa}$. The magnitude of the saturation angle $\beta_{\text {sat }}$ is dependent upon details of the XAFS analysis. If the $\mathrm{Cu}(1)-\mathrm{O}(4)-$ $\mathrm{Cu}(2)$ path is assumed to be linear at 1 bar, then $\beta_{\text {sat }}$ is found to be $12^{\circ}$. However, if the presence of static or dynamical displacements of the $\mathrm{O}(4)$ atom from the c-axis, as reported in ion channeling and neutron diffraction experiments at 1 bar, are included in the XAFS analysis by assuming that the path is already buckled by $3^{\circ}$ at 1 bar, then $\beta_{\text {sat }} \sim 8.5^{\circ}$. Because the multiple scattering effect decreases as $\beta$ increases it was not possible to follow this behavior above 6.5 GPa where the XAFS contributions from the $\mathrm{Cu}(1)-\mathrm{O}(4)-\mathrm{Cu}(2)$ path become too weak.

The anisotropy of the pressure depencence of $T_{c}$ has been reported from the discontinuities in the high resolution thermal expansion data. According to these studies the pressure derivative of $T_{c}$ is large and opposite in sign along the $a$ - and $b$ - axes but small along the $c$-axis, leading to an overall low pressure dependence of $T_{c}$ for $\mathrm{YBa}_{2} \mathrm{Cu}_{3} \mathrm{O}_{7-\delta} .{ }^{29}$ The buckled structure can have important aspects explaining these anisotropies. Burns ${ }^{30}$ proposing a coupling of superconductivity to the shear deformation along (110), showed $T_{c}$ increases with shear stress up to a point and then decreases.

The buckled structure can also have a contribution to $T_{c}$ according to the resonating valence bond model of Anderson ${ }^{31}$ in which the logarithmic volume derivative of $T_{c}$ is related explicitly to carrier concentration and to the transfer integrals parallel $\left(t_{\|}\right)$and perpendicular $\left(t_{\perp}\right)$ to the $\mathrm{CuO}_{2}$ planes. With the distortion of the $\mathrm{O}(4), t_{\perp}$ is expected to decrease. However the effect of this decrease on the pressure derivative of $T_{c}$ is expected to be small since, according to the model, the dominant contribution to the change in $T_{c}$ comes from the carrier concentration term. 


\section{Publications}

"XAFS Study of Pressure Induced Amorphization," F. Wang and R. Ingalls, in High Pressure Science and Technology, W. Trzeciakowski, Ed. (World Scientific, Singapore, 1996) p. 289.

"XAFS Study of the B1-B2 Transition in RbCl," R. Ingalls, S. Jones and F. Wang, in High Pressure Science and Technology, W. Trzeciakowski, Ed. (World Scientific, Singapore, (1996) p. 432.

"Electronic Structure of RbBr under Phase Transition: X-ray Absorption Near Edge Structure Analysis," A.V. Soldatov, I.E. Stekhin and R. Ingalls, J. Phys.: Condens. Matter 8, 7829 (1996)

"The Effect of Hydrostatic Pressure on the Local Structure of $\mathrm{K}_{1-x} \mathrm{Na}_{x} \mathrm{TaO}_{3}$ and $\mathrm{KTa}_{1-x} \mathrm{Nb}_{x} \mathrm{O}_{3}$, F. Wang, B. Ravel, Y. Yacoby and E.A. Stern and R. Ingalls, J. de Phys. IV 7, C2-1225 (1997).

"Local Structural Changes in $\mathrm{KNbO}_{3}$ under High Pressure," A.I. Frenkel, F.M. Wang, S. Kelly, R. Ingalls, D. Haskel, E.A. Stern and Y. Yacoby, Phys. Rev. B 56, 10,869 (1997).

"Iron bcc-hcp Transition: Local Structure from X-ray Absorption Fine Structure," F. M. Wang and R. Ingalls, Phys. Rev. B57, 5647(1998).

"X-ray Absorption Fine Structure Study of the B1 to B2 Phase Transition in RbCl," S. Kelly, R. Ingalls, F. Wang, B. Ravel and D. Haskel, Phys. Rev. B 57, 7543 (1998).

"Pressure-induced Chain Buckling in $\mathrm{YBa}_{2} \mathrm{Cu}_{3} \mathrm{O}_{7-\delta}$, A. Sahiner, E. D. Crozier, D. T. Jiang and R. Ingalls, Phys. Rev. B (in press).

"X-ray Absorption Fine Structure Determination of Pressure Induced Bond Angle Changes in $\mathrm{ReO}_{3}, " \mathrm{~B}$. Houser and R. Ingalls, Phys. Rev. B (submitted).

"Pressure-induced Changes in the Local Structure of Pure and Optimally Doped $\mathrm{La}_{2-x} \mathrm{Sr}_{x} \mathrm{CuO}_{4}, "$ D. Haskel, E.A. Stern, S. Kelly and R. Ingalls, Phys. Rev. B (in preparation).

"XAFS Studies of the Pressure-Induced Mixed-Valence Transition in SmSe," K.R. Bauchspiess, E.D. Crozier and R. Ingalls, Phys. Rev. B (in preparation)

"Phase Changes in $\mathrm{AgCl}$ at High Pressure: XAFS Measurements," S. Kelly, R. Ingalls F.M. Wang and A. Voronel, Phys. Rev. B (in preparation).

\section{Reports and Presentations}

"Local Structural Changes in $\mathrm{KNbO}_{3}$ under High Pressure," A.I. Frenkel, F.M. Wang, S. Kelly, R. Ingalls, D. Haskel, E.A. Stern and Y. Yacoby, AIRAPT Conference, Kyoto, Japan, Aug. 25-29, 1997.

"XAFS Study of the Iron bcc-hcp Transition," F. M. Wang and R. Ingalls, AIRAPT Conference, Kyoto, Japan, Aug. 25-29, 1997.

"Local Structure of $\mathrm{AgCl} . \mathrm{AgBr}$ and $\mathrm{AgCl}_{x} \mathrm{Br}_{1-x}$ under pressure," S. Kelly, F. M. Wang and A. Voronel, Bull. Am. Phys. Soc. 43, 498 (1998). 


\section{Personnel}

Robert Ingalls - Principal Investigator

Fuming Wang - Postdoctoral Associate

Shelley Kelly- Graduate Student

B. Houser - Collaborator (Eastern Washington University)

E.A. Stern, D. Haskel and J.J. Rehr - Collaborators (Univ. of Washington)

E. D. Crozier - Collaborator (Simon Fraser University)

Y. Yacoby - Collaborator (Racah Institute)

A. Voronel - Collaborator (Tel Aviv University)

A. Frenkel - Collaborator (University of Illinois and NSLS)

A. Soldatov - Collaborator (Rostov State University)

\section{PhD Thesis}

"XAFS Study of Solid-solid Transitions under High Pressure" Fuming $M$. Wang University of Washington, March, 1998 


\section{REFERENCES}

${ }^{1}$ E.A. Stern and S.M. Heald, in Handbook on Synchrotron Radiation, E.E. Koch, Ed. (North-Holland, N. Y. 1993), Vol. 1

${ }^{2}$ R. Ingalls et al., J. Appl. Phys. 51, 3158 (1980).

${ }^{3}$ A.I. Frenkel et al., Phys. Rev. B 56, 10,869 (1997).

${ }^{4}$ K.H. Kim et al., Mat. Res. Soc. Symp. Proc. 172, 291 (1990).

${ }^{5}$ A.W. Hewat, J. Phys. C: Solid State Phys. 6, 2559 (1973).

${ }^{6}$ D. Gourdain et al., Phys. Rev. 52, 3108 (1995).

${ }^{7}$ Z.X. Shen et al., Phys. Rev. 52, 3976 (1995).

${ }^{8}$ E.A. Stern et al., Physica B, 208\&209, 117 (1995).

${ }^{9}$ S.I. Zabinsky et al., Phys. Rev. 52, 2995 (1995).

${ }^{10} \mathrm{~F}$. Wang et al., J. de Phys. IV 7, C2-1225 (1997).

${ }^{11}$ T.G. Davis, Phys. Rev. B 5, 2530 (1972).

${ }^{12}$ B. Rechav et al., Phys. Rev. Lett. 72, 1352 (1994).

${ }^{13}$ N. Sicron et al., Phys. Rev. B 50, 13168 (1994).

${ }^{14}$ B. Houser et al., Physica B 208\&209, 323 (1995).

${ }^{15}$ F. M. Wang and R. Ingalls, Phys. Rev. B57, 5647(1998).

${ }^{16}$ K. Mao et al., J. Appl. Phys. 38, 272 (1967).

${ }^{17}$ A. P. Jephcoat et al., J. Geophys. Res. 91, 4677 (1986).

${ }^{18}$ W. A. Bassett and E. Huang, Science 238, 780 (1987).

${ }^{19}$ D. Bancroft et al., J. Appl. Phys. 27, 291 (1956).

${ }^{20}$ W. G. Burgers, Physica 1, 561 (1934).

${ }^{21}$ S. Kelly et al., Rev. B 57, 7543 (1998).

${ }^{22}$ S. Vaidya and G. Kennedy, J. Phys. Chem. Solids 32, 951 (1971).

${ }^{23}$ H. Fujiwara et al., J. Phys. Soc. Jpn. 52, 1665 (1983).

${ }^{24}$ K. Kusaba et al., J. Phys. Chem. Sol. 56, 408 (1995).

${ }^{25}$ P. G. Radaelli et al., Phys. Rev. B 49, 4163 (1994).

${ }^{26}$ N. Yamada and M. Ido, Physica C 203, 240 (1992).

${ }^{27} \mathrm{~A}$. Voronel and A. Frenkel (private communication).

${ }^{28}$ H. Takahashi et al., Phys. Rev. B. 50, 3221 (1994). 
